\title{
Optimization of Jelly Made with Rubus coreanus (Bokbunja) Using Response Surface Methodology
}

\author{
Nami Joo ${ }^{1 \dagger}$, Sun-Mee Lee ${ }^{1}$, and Hee Sun Jeong ${ }^{2}$ \\ ${ }^{1}$ Department of Food \& Nutrition and ${ }^{2}$ Graduate School of Professional Studies Traditional Culture and Arts, \\ Sookmyung Women's University, Seoul 140-742, Korea
}

\begin{abstract}
The purpose of this study was to find new applications for Rubus coreanus and to produce new products. Jelly prepared with Rubus coreanus was studied and analyzed with regard to its composition, heology and sensory evaluation. The technique of response surface methodology was used to analyze the results, which showed 16 experimental points including 2 replicates for Rubus coreanus juice, gelatin and sucrose. Rheological characteristics such as lightness, redness, yellowness and hardness, springness, chewiness and gumminess were shown to be significant, and these were mostly influenced by the content of Rubus coreanus juice. Significant sensory characteristics such as color, flavor, transparency, taste and the overall quality were also found to be greatly influenced by Rubus coreanus juice and gelatin in general. Based on the overlapping categonies of factors that satisfied all sensory categories, the maximally optimized point was taken as the middle point. This value was detemined to be $43.28 \mathrm{~g}$ of Rubus coreanus juice and $9.19 \mathrm{~g}$ of gelatin for every $140.00 \mathrm{~g}$ of sucrose.
\end{abstract}

Key words: Rubus coreanus, jelly, response surface methodology, optimization, sensory evaluation

\section{INTRODUCTION}

With the current trend in diet habits and lack of exercise, individuals are suffering from diabetes, various types of cancers, diseases of circulatory organs and high blood pressure. There is thus a growing concern health foods in our society. One study demonstrated the beneficial effects of fruit and vegetable consumption on indices of health for a sample population (1). In particular antioxidants and phytochemicals in fruits and vegetables reduce the risk of several chronic and degenerative diseases (2).

The dried fruit of Rubus coreanus is well-known in Korea and is commonly referred to as "Bokbunja" (3). It has been employed as traditional medicine for centuries. Rubus coreanus contains a group of phytochemicals providing nutrients like phosphorus, iron, calcium, vitamin $\mathrm{C}$, organic acids etc. and phenolic compounds like quercetin, ellagic acids and sanguiin H-5 (4). Pharmacological studies of Rubus coreanus have revealed that it is capable of suppressing Vibrio cholerae, Tubercle bacillus, Staphylococcus aureus $(5,6)$. Antioxidant activity (7), an anti-cancer activator (8), increment in immunity activity, hormone secretion promotion, viral hepatitis type B inhibitive action and weight control effects (9) have been observed in Rubus coreanus.
Jellies are a widely consumed dessert, appreciated for their texture and ease of cooking. The use of natural ingredients, exhibiting special properties and providing specific health benefits, is a very attractive way to design new food products (10). The objectives of the present study were to assess the effects of three factors (Rubus coreanus juice, sucrose and gelatin) on the physicochemical characteristics of Rubus coreanus jellies using response surface methodology (RSM) and to determine the optimal level of each of these factors.

\section{MATERIALS AND METHODS}

\section{Materials}

Rubus coreanus grown in Gochang (Korea) was purchased directly from the producers. These were used in the study by squeezing the juice from Rubus coreanus (OSK, Korea) after putting them in a deep-freezer at $-20^{\circ} \mathrm{C}$. Also, sucrose (CJ, Korea), gelatin (Knox, USA) and citric acid (Shinwon industrial Co., Ltd., Korea) were used. Potable water was available at the processing site.

\section{Expenimental design}

The Design Expert 7 Program was used to plan the study as well as for data analysis and optimization analysis of Rubus coreanus jelly. As independent variables,

†Corresponding author. E-mail: namij@sm.ac.kr Phone: +82-2-710-9471, Fax: +82-2-710-9479 
the three factors chosen were Rubus coreanus juice, gelatin and sucrose. As dependent variables, color values (L, a, b), textural evaluation (hardness, springiness, chewiness, gumminess, and cohesiveness) and sensory evaluation (color, flavor, transparency, taste, hardness, springiness, and overall quality) were chosen. Through pre-examination the maximum and minimum range of Rubus coreanus juice, sucrose and gelatin were determined to be $20 \sim 60 \mathrm{~g}, 8 \sim 16 \mathrm{~g}, 60 \sim 140 \mathrm{~g}$ respectively. Rubus coreanus juice and water were 400 $\mathrm{g}$ and citric acid was limited to $2 \mathrm{~g}$. The experimental points of Central Composite consist of the most central point, \pm apoint (axial point) and \pm 1 level point (factorial point), and between these experimental points, there existed an iterative point for the selection of a model and the verification of fitness lack. Accordingly, when each established scope was inputted, forming 16 experimental points, 2 iterative points were selected through the establishment of replication (11). The mixture ratios for the jelly to Rubus coreanus juice are as shown in Table 1.

\section{Preparation of jelly}

The standard formulation for product treatment consisted of Rubus coreanus juice, water, gelatin, sucrose and citric acid. Rubus coreanus juice was mixed with water. The gelatin was dissolved using half of the mixed Rubus coreanus juice and water for $10 \mathrm{~min}$. The remaining half of the mixed Rubus coreanus juice and water was boiled to $70^{\circ} \mathrm{C}$. Afterward, the sucrose was added to the mixture and boiled to $100^{\circ} \mathrm{C}$ and then let to cool.

Next, the first half of the mixed Rubus coreanus juice and water were added to this solution and stirred at regu-

Table 1. Experimental design for Rubus coreanus jelly

\begin{tabular}{cccc}
\hline \multirow{2}{*}{$\begin{array}{c}\text { Sample } \\
\text { No. }\end{array}$} & \multicolumn{3}{c}{ Variable level $^{2}$} \\
\cline { 2 - 4 } & $\mathrm{X}_{1}$ & $\mathrm{X}_{2}$ & $\mathrm{X}_{3}$ \\
\hline 1 & 20.00 & 8.00 & 60.00 \\
2 & 60.00 & 8.00 & 60.00 \\
3 & 20.00 & 16.00 & 60.00 \\
4 & 60.00 & 16.00 & 60.00 \\
5 & 20.00 & 8.00 & 140.00 \\
6 & 60.00 & 8.00 & 140.00 \\
7 & 20.00 & 16.00 & 140.00 \\
8 & 60.00 & 16.00 & 140.00 \\
9 & 20.00 & 12.00 & 100.00 \\
10 & 60.00 & 12.00 & 100.00 \\
11 & 40.00 & 8.00 & 100.00 \\
12 & 40.00 & 16.00 & 100.00 \\
13 & 40.00 & 12.00 & 60.00 \\
14 & 40.00 & 12.00 & 140.00 \\
15 & 40.00 & 12.00 & 100.00 \\
16 & 40.00 & 12.00 & 100.00 \\
\hline
\end{tabular}

${ }^{1)}$ Sample No. : The number of experimental conditions by central composite design.

${ }^{2)} \mathrm{X}_{1}$ : Rubus coreanus juice, $\mathrm{X}_{2}$ : gelatin, $\mathrm{X}_{3}$ : sucrose. lar speed for $3 \mathrm{~min}$, prior to addition of citric acid. The completed solution was placed in a container $(15 \times$ $15 \times 4 \mathrm{~cm}$ ), and solidified at room temperature for 1 hour and then refrigerated at $4^{\circ} \mathrm{C}$ for 5 hours. Finally, the jelly was cut into portions of equal size $(2 \times 2 \times 3 \mathrm{~cm})$.

\section{Color measurement}

The color values ( $\mathrm{L}, \mathrm{a}$, and $\mathrm{b}$ value) of the Rubus coreanus jelly were measured using a colorimeter (Colormeter CR-200, Minolta Co., Japan). The colorimeter was calibrated using a standard white plate with $\mathrm{L}$, a, and $\mathrm{b}$ values of $97.26,-0.07$ and +1.86 , respectively. Three measurements were made for each treatment.

\section{Texture analysis}

The texture of Rubus coreanus jelly was measured using a texture analyzer (model TAXT express, Stable Micro system Ltd., UK). TPA parameters (hardness, springiness, chewiness, gumminess, and cohesiveness) were calculated. The operating conditions of the texture analyzer are shown in Table 2 .

\section{Sensory evaluation}

A panel consisting of 16 students at Sookmyung Women's University was chosen. The panelists were asked to score the color, flavor, transparency, taste, hardness, springiness, and overall quality of the Rubus coreanus jelly with points ranging from 1 (dislike extremely) to 7 (like extremely). The Rubus coreanus jelly prepared for each test sample was recorded with a random 4-digit number. Water was provided for mouth-rinsing between consecutive evaluations.

\section{Optimization}

Through numerical optimization of a Canonical Model and graphical optimization, the optimal quantities of Rubus coreanus juice, sucrose and gelatin was chosen, by selecting the optimal point using the point found through point prediction. For numerical optimization, the goal area was set with the highest point of the sensory test from the coefficients of the standard canonical model. Through numerical optimization, the optimal point showing the highest desirability was selected using

Table 2. Operating conditions for texture analyzer

\begin{tabular}{cc}
\hline Instrument & Texture analyzer \\
\hline Type & Compression test \\
& (Texture Profile Analysis test) \\
Adaptor type & 3 \\
Pre-test speed & $3 \mathrm{~mm} / \mathrm{sec}$ \\
Test speed & $3 \mathrm{~mm} / \mathrm{sec}$ \\
Post test speed & $3 \mathrm{~mm} / \mathrm{sec}$ \\
Distance & $15 \mathrm{~mm}$ \\
Trigger force & $35 \mathrm{~g}$ \\
\hline
\end{tabular}


the following formula.

$$
\mathrm{D}=\left(\mathrm{d}_{1} \times \mathrm{d}_{2} \times \cdots \times \mathrm{d}_{\mathrm{n}}\right)^{\frac{1}{n}}=\left(\prod_{\mathrm{i}=1}^{\mathrm{n}} \mathrm{d}_{\mathrm{i}}\right)^{\frac{1}{\mathrm{n}}}
$$

Here, $\mathrm{D}$ is the overall desirability, $\mathrm{d}$ is each desirability and $\mathrm{n}$ is the number of responses.

\section{Statistical analysis}

Statistical analysis of variance (ANOVA) and multiple regressions were performed using the Design-Expert 7 program (Stat-Easy Co., Minneapolis) to fit the equation. The results included the significance of the model and of each of its terms, the estimated model coefficients, the coefficient of determination, and the lack of fit test.

\section{RESULTS AND DISCUSSION}

\section{Physicochemical characteristics}

According to the Central Composite Design, which was used to optimize the manufacturing conditions for Rubus coreanus jellies, the results of physicochemical measurements from 16 conditions with 3 variables are as follows.

Color values: The color values from 16 conditions with 3 variables are listed in Table 3 . The model equations and the coefficients of determination of the model equation are given in Table 4. The values of $\mathrm{L}$, a and $\mathrm{b}$ were within the ranges of $19.14 \sim 24.43,0.93 \sim 2.56$ and $-0.51 \sim-0.11$, respectively. Increased Rubus coreanus juice significantly decreased $\mathrm{L} \quad(\mathrm{p}<0.01)$, a $(p<0.05)$ and $b(p<0.05)$. Shown in Fig. 1 is the re- sponse surface for the effect of Rubus coreanus juice, gelatin and sucrose on color values of the Rubus coreanus jelly.

Textural characteristics: The results of texture parameters are shown in Table 3. The model equations and the coefficients of determination of the model equation are described in Table 4. Significant values in hardness $(p<0.001)$, springiness $(p<0.01)$, chewiness $(p<0.01)$, gumminess $(\mathrm{p}<0.05)$ are shown. Moreover, the addition of gelatin had a positive effect on the texture analyzer. Increased gelatin significantly increased the texture parameters. These results were in accordance with a previous study in which the texture of Noni jelly was estimated by a subjective method and was shown to be influenced by the content of gelatin (12). The correlation between ingredients and the cohesiveness of jelly with Rubus coreanus was not significant. Shown in Fig. 2 is the response surface for the effect of Rubus coreanus juice, gelatin and sucrose on textural characteristics of Rubus coreanus jelly.

\section{Sensory evaluation}

The values of color, flavor, transparency, taste, hardness, springiness and overall quality were within the ranges of $3.67 \sim 5.33,3.67 \sim 5.50,2.67 \sim 6.33,2.83 \sim$ $5.17,3.33 \sim 5.33,2.83 \sim 5.17,3.17 \sim 5.67$, respectively (Table 5). The model equations and coefficients of determination of the model equation are given in Table 6 . The sensory evaluation results showed significant values in color $(\mathrm{p}<0.01)$, flavor $(\mathrm{p}<0.01)$, transparency $(\mathrm{p}<$ $0.001)$, taste $(\mathrm{p}<0.05)$ and overall quality $(\mathrm{p}<0.01)$. An

Table 3. Experimental combinations and data under various conditions of Rubus coreanus juice, gelatin, sucrose, and their responses

\begin{tabular}{|c|c|c|c|c|c|c|c|c|c|c|c|}
\hline \multirow{2}{*}{$\begin{array}{c}\text { Sample } \\
\text { No. }\end{array}$} & \multicolumn{3}{|c|}{ Variable level $^{2}$} & \multicolumn{8}{|c|}{ Responses $^{3)}$} \\
\hline & $\mathrm{X}_{1}$ & $\mathrm{X}_{2}$ & $\mathrm{X}_{3}$ & $\mathrm{Y}_{1}$ & $\mathrm{Y}_{2}$ & $\mathrm{Y}_{3}$ & $\mathrm{Y}_{4}$ & $\mathrm{Y}_{5}$ & $\mathrm{Y}_{6}$ & $\mathrm{Y}_{7}$ & $\mathrm{Y}_{8}$ \\
\hline 1 & 20 & 8 & 60 & 19.14 & 1.98 & -0.25 & 2219.30 & 0.42 & 161.65 & 400.04 & 0.18 \\
\hline 2 & 60 & 8 & 60 & 19.90 & 2.19 & -0.21 & 1622.73 & 0.40 & 141.71 & 364.52 & 0.22 \\
\hline 3 & 20 & 16 & 60 & 21.42 & 1.83 & -0.33 & 4972.03 & 0.57 & 565.04 & 945.11 & 0.20 \\
\hline 4 & 60 & 16 & 60 & 19.32 & 1.47 & -0.33 & 5072.87 & 0.59 & 641.49 & 1065.54 & 0.22 \\
\hline 5 & 20 & 8 & 140 & 24.00 & 2.34 & -0.25 & 4425.15 & 0.33 & 369.26 & 1141.42 & 0.26 \\
\hline 6 & 60 & 8 & 140 & 24.43 & 0.94 & -0.51 & 3006.21 & 0.43 & 780.05 & 1836.20 & 0.31 \\
\hline 7 & 20 & 16 & 140 & 22.46 & 2.02 & -0.22 & 5616.23 & 0.85 & 1556.32 & 1831.85 & 0.33 \\
\hline 8 & 60 & 16 & 140 & 20.83 & 0.93 & -0.28 & 6560.30 & 0.72 & 819.15 & 1133.56 & 0.17 \\
\hline 9 & 20 & 12 & 100 & 21.79 & 2.22 & -0.16 & 5184.13 & 0.75 & 878.03 & 1170.97 & 0.23 \\
\hline 10 & 60 & 12 & 100 & 22.80 & 2.37 & -0.17 & 3639.27 & 0.65 & 540.40 & 835.22 & 0.23 \\
\hline 11 & 40 & 8 & 100 & 23.08 & 2.31 & -0.17 & 2770.97 & 0.46 & 355.19 & 763.68 & 0.27 \\
\hline 12 & 40 & 16 & 100 & 20.28 & 1.83 & -0.11 & 5535.93 & 0.74 & 1577.88 & 2135.69 & 0.39 \\
\hline 13 & 40 & 12 & 60 & 21.62 & 2.56 & -0.15 & 4068.80 & 0.73 & 667.94 & 915.48 & 0.22 \\
\hline 14 & 40 & 12 & 140 & 23.38 & 2.00 & -0.23 & 4943.27 & 0.67 & 965.20 & 1442.58 & 0.29 \\
\hline 15 & 40 & 12 & 100 & 22.74 & 2.34 & -0.21 & 3731.67 & 0.68 & 696.25 & 1021.91 & 0.27 \\
\hline 16 & 40 & 12 & 100 & 22.74 & 2.15 & -0.14 & 3667.40 & 0.74 & 801.16 & 1086.07 & 0.30 \\
\hline
\end{tabular}

${ }^{1)}$ Sample No.: The number of experimental conditions by central composite design.

${ }^{2)} \mathrm{X}_{1}$ : Rubus coreanus juice $(20 \sim 60 \mathrm{~g}), \mathrm{X}_{2}$ : gelatin $(8 \sim 16 \mathrm{~g}), \mathrm{X}_{3}$ : sucrose $(60 \sim 40 \mathrm{~g})$.

${ }^{3)} \mathrm{Y}_{1}$ : L (white $+100 \leftrightarrow 0$ black), $\mathrm{Y}_{2}$ : a (red $+60 \leftrightarrow-60$ green), $\mathrm{Y}_{3}$ : b (yellow $+60 \leftrightarrow-60$ blue), $\mathrm{Y}_{4}$ : hardness, $\mathrm{Y}_{5}$ : springiness, $\mathrm{Y}_{6}$ : chewiness, $\mathrm{Y}_{7}$ : gumminess, $\mathrm{Y}_{8}$ : cohesiveness. 
Table 4. Analysis of the predicted model equation for the color values and textural characteristics of Rubus coreanus jelly

\begin{tabular}{|c|c|c|c|c|c|}
\hline Responses $^{1)}$ & Model & $\begin{array}{c}\mathrm{R}- \\
\text { squared }\end{array}$ & $\begin{array}{c}\text { F- } \\
\text { value }\end{array}$ & $\begin{array}{l}\text { P-value } \\
\text { Prob }>F^{2)}\end{array}$ & $\begin{array}{l}\text { Equation of on terms } \\
\text { of pseudo component }\end{array}$ \\
\hline $\mathrm{Y}_{1}$ & $2 \mathrm{FI}$ & 0.8089 & 6.35 & $0.0074^{* *}$ & $\begin{array}{l}21.87-0.15 \mathrm{X}_{1}-0.62 \mathrm{X}_{2}+1.37 \mathrm{X}_{3}-0.61 \mathrm{X}_{1} \mathrm{X}_{2}+0.018 \mathrm{X}_{1} \mathrm{X}_{3} \\
-0.86 \mathrm{X}_{2} \mathrm{X}_{3}\end{array}$ \\
\hline $\mathrm{Y}_{2}$ & Quadratic & 0.8650 & 4.27 & $0.0456^{*}$ & $\begin{array}{l}2.37-0.25 X_{1}-0.17 X_{2}-0.18 X_{3}-0032 X_{1} X_{2}-0.29 X_{1} X_{3} \\
+0.068 X_{2} X_{3}-0.13 X_{1}^{2}-0.36 X_{2}^{2}-0.15 X_{3}^{2}\end{array}$ \\
\hline $\mathrm{Y}_{3}$ & Quadratic & 0.8667 & 4.34 & $0.0441^{*}$ & $\begin{array}{l}-0.13-0.029 \mathrm{X}_{1}+0.012 \mathrm{X}_{2}-0.022 \mathrm{X}_{3}+0.020 \mathrm{X}_{1} \mathrm{X}_{2} \\
-0.045 \mathrm{X}_{1} \mathrm{X}_{3}+0.058 \mathrm{X}_{2} \mathrm{X}_{3}-0.053 \mathrm{X}_{1}^{2}-0.028 \mathrm{X}_{2}^{2}-0.078 \mathrm{X}_{3}^{2}\end{array}$ \\
\hline $\mathrm{Y}_{4}$ & $2 \mathrm{FI}$ & 0.8962 & 12.95 & $0.0006^{* * *}$ & $\begin{array}{l}4002.27551 .55 X_{1}+1671.30 X_{2}+359.54 X_{3}+757.55 X_{1} X_{2} \\
-372.39 X_{1} X_{3}+192.79 X_{2} X_{3}\end{array}$ \\
\hline $\mathrm{Y}_{5}$ & Quadratic & 0.9352 & 9.62 & $0.0061^{* *}$ & $\begin{array}{l}0.72-0.013 X_{1}+0.14 X_{2}+0.029 X_{3}-0.024 X_{1} X_{2}-3.750 E \\
-003 X_{1} X_{3}+0.059 X_{2} X_{3}-0.027 X_{1}^{2}-0.13 X_{2}^{2}-0.027 X_{3}^{2}\end{array}$ \\
\hline $\mathrm{Y}_{6}$ & Linear & 0.6757 & 8.34 & $0.0029^{* *}$ & $719.79-60.75 X_{1}+335.20 X_{2}+231.21 X_{3}$ \\
\hline $\mathrm{Y}_{7}$ & Linear & 0.5793 & 5.51 & $0.0130^{*}$ & $1130.62-25.43 X_{1}+260.59 X_{2}+369.49 X_{3}$ \\
\hline
\end{tabular}

${ }^{1)} \mathrm{Y}_{1}$ : L (white $+100 \leftrightarrow 0$ black), $\mathrm{Y}_{2}$ : a (red $+60 \leftrightarrow-60$ green), $\mathrm{Y}_{3}: \mathrm{b}$ (yellow $+60 \leftrightarrow-60$ blue), $\mathrm{Y}_{4}$ : hardness, $\mathrm{Y}_{5}$ : springiness, $\mathrm{Y}_{6}$ : chewiness, $\mathrm{Y}_{7}$ : gumminess.

$\left.{ }^{2}\right)^{*} \mathrm{p}<0.05, \stackrel{\mathrm{p}}{\mathrm{k}}<0.01,{ }^{* * * *} \mathrm{p}<0.001$.

${ }^{3)} \mathrm{X}_{1}$ : Rubus coreanus juice $(\mathrm{g}), \mathrm{X}_{2}$ : gelatin $(\mathrm{g}), \mathrm{X}_{3}$ : sucrose $(\mathrm{g})$.
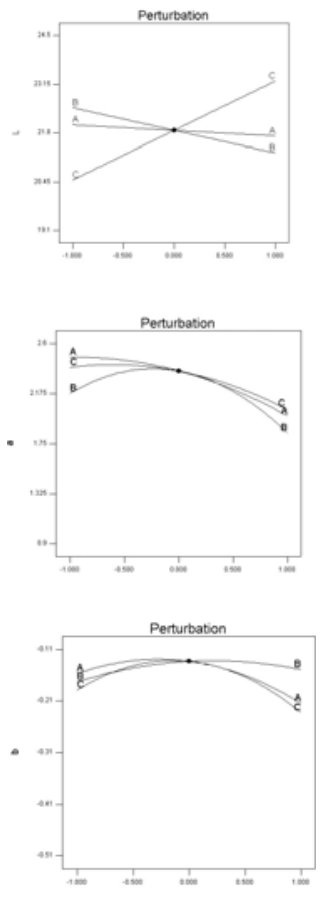
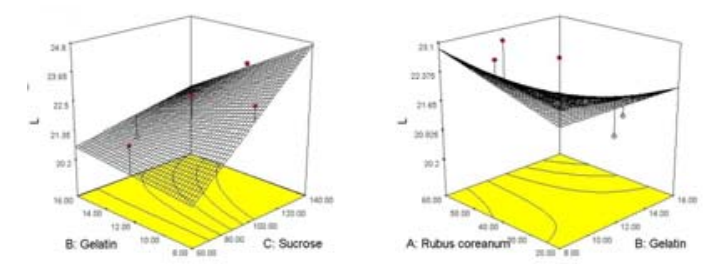

Color (L)
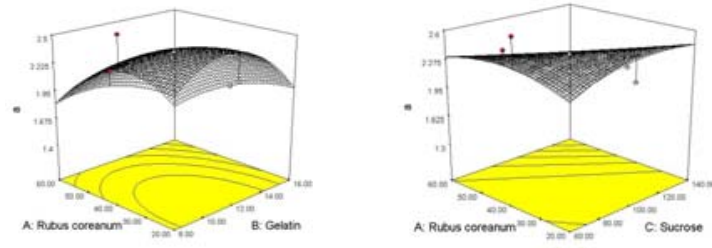

Color (a)
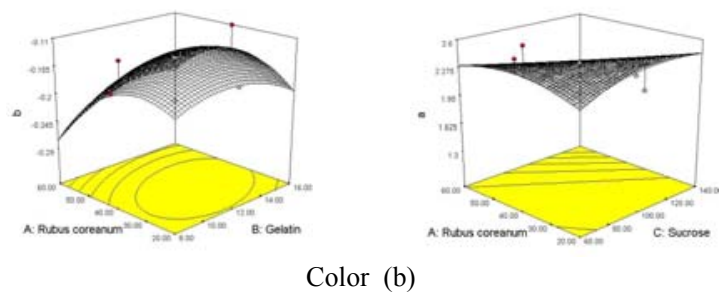
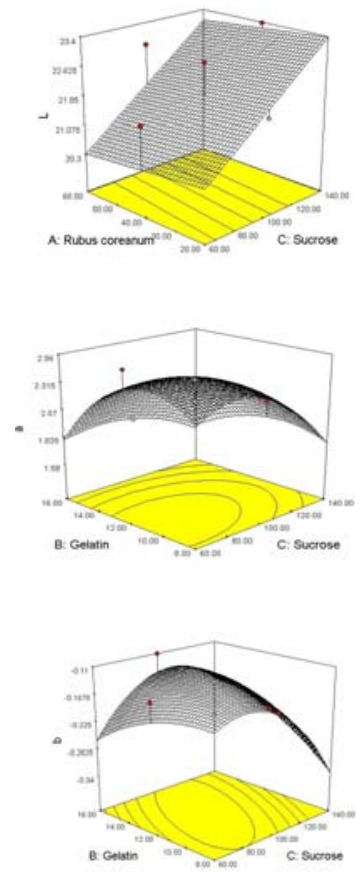

gelatin $(B) \times$ sucrose $(C)$

Fig. 1. Response surfaces for the effect of Rubus coreanus juice (A), gelatin (B), sucrose (C) on color of Rubus coreanus jelly.

increase in Rubus coreanus juice decreased the preference in color. But, as more sucrose was added, the preference in color increased. A larger portion of Rubus coreanus juice increased the preference in flavor. It was shown that with more Rubus coreanus juice, the transparency of the jelly decreased. Addition of gelatin and sucrose showed little influence on flavor or transparency.
A greater addition of Rubus coreanus juice increased the preference in taste. But, as more gelatin was added, the preference in taste decreased; sucrose had little influence on the taste. Correlation between ingredients and the hardness and springiness of jelly with Rubus coreanus were not significant. The texture characteristic of gel, hardness and springiness were not significant but 

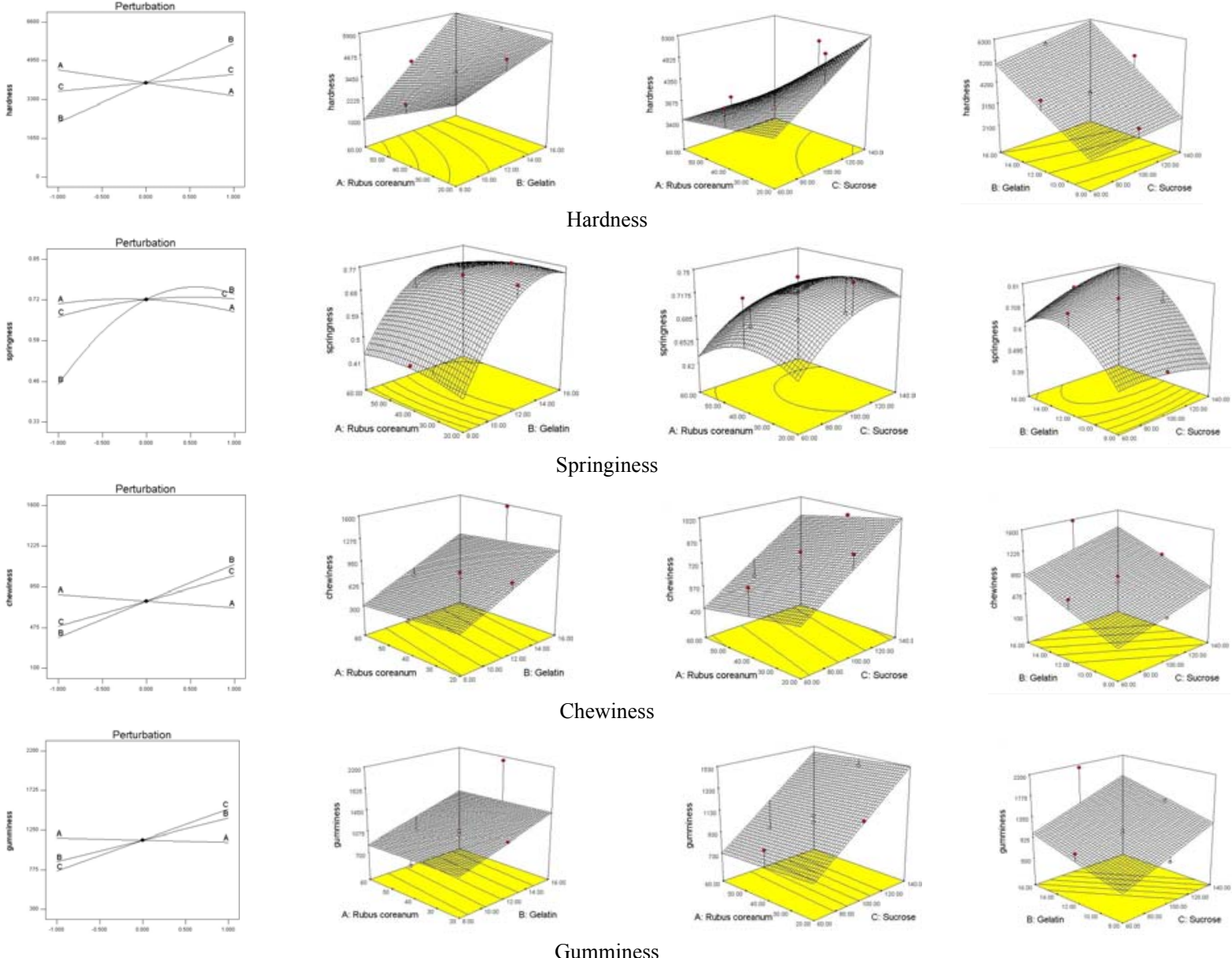

Rubus coreanus juice $(\mathrm{A}) \times$ gelatin (B) Rubus coreanus juice $(\mathrm{A}) \times$ sucrose $(\mathrm{C}) \quad$ gelatin $(\mathrm{B}) \times$ sucrose $(\mathrm{C})$

Fig. 2. Response surfaces for the effect of Rubus coreanus juice (A), gelatin (B), sucrose (C) on textural characteristics of Rubus coreanus jelly.

Table 5. Experimental combinations and data under various conditions of Rubus coreanus juice, gelatin, sucrose, and their responses

\begin{tabular}{|c|c|c|c|c|c|c|c|c|c|c|}
\hline \multirow{2}{*}{$\begin{array}{c}\text { Sample } \\
\text { No. }\end{array}$} & \multicolumn{3}{|c|}{ Variable level $^{2)}$} & \multicolumn{7}{|c|}{ Responses $^{3)}$} \\
\hline & $\mathrm{X}_{1}$ & $\mathrm{X}_{2}$ & $\mathrm{X}_{3}$ & $\mathrm{Y}_{1}$ & $\mathrm{Y}_{2}$ & $\mathrm{Y}_{3}$ & $\mathrm{Y}_{4}$ & $\mathrm{Y}_{5}$ & $\mathrm{Y}_{6}$ & $Y_{7}$ \\
\hline 1 & 20 & 8 & 60 & 4.17 & 3.83 & 4.83 & 4.33 & 4.17 & 3.67 & 4.00 \\
\hline 2 & 60 & 8 & 60 & 4.50 & 5.00 & 3.50 & 3.33 & 3.67 & 3.50 & 3.83 \\
\hline 3 & 20 & 16 & 60 & 4.33 & 4.17 & 5.33 & 3.00 & 4.67 & 4.33 & 3.83 \\
\hline 4 & 60 & 16 & 60 & 4.17 & 4.67 & 3.67 & 3.83 & 5.33 & 5.17 & 3.17 \\
\hline 5 & 20 & 8 & 140 & 5.33 & 3.67 & 5.33 & 4.50 & 3.33 & 3.17 & 4.17 \\
\hline 6 & 60 & 8 & 140 & 4.17 & 4.50 & 4.17 & 5.17 & 5.00 & 5.00 & 4.33 \\
\hline 7 & 20 & 16 & 140 & 5.00 & 3.83 & 5.33 & 3.00 & 4.17 & 4.33 & 4.50 \\
\hline 8 & 60 & 16 & 140 & 4.33 & 5.50 & 3.17 & 4.33 & 4.17 & 4.33 & 3.17 \\
\hline 9 & 20 & 12 & 100 & 5.33 & 3.67 & 6.33 & 4.83 & 4.83 & 4.50 & 4.17 \\
\hline 10 & 60 & 12 & 100 & 3.67 & 5.33 & 2.67 & 4.50 & 4.83 & 5.00 & 4.17 \\
\hline 11 & 40 & 8 & 100 & 4.67 & 4.83 & 5.00 & 4.67 & 4.00 & 2.83 & 4.17 \\
\hline 12 & 40 & 16 & 100 & 4.67 & 4.33 & 4.33 & 4.33 & 5.17 & 5.00 & 4.50 \\
\hline 13 & 40 & 12 & 60 & 5.00 & 4.33 & 3.83 & 4.50 & 5.17 & 5.17 & 4.50 \\
\hline 14 & 40 & 12 & 140 & 5.17 & 4.17 & 4.83 & 5.00 & 4.83 & 5.17 & 4.67 \\
\hline 15 & 40 & 12 & 100 & 4.50 & 3.67 & 4.33 & 4.67 & 4.83 & 4.17 & 5.67 \\
\hline 16 & 40 & 12 & 100 & 4.17 & 4.33 & 3.83 & 2.83 & 4.33 & 4.17 & 3.17 \\
\hline
\end{tabular}

${ }^{1)}$ Sample No.: The number of experimental conditions by central composite design.

${ }^{2)} \mathrm{X}_{1}$ : Rubus coreanus juice $(20 \sim 60 \mathrm{~g}), \mathrm{X}_{2}$ : gelatin $(8 \sim 16 \mathrm{~g}) . \mathrm{X}_{3}$ : sucrose $(60 \sim 140 \mathrm{~g})$.

${ }^{3)} \mathrm{Y}_{1}$ : color, $\mathrm{Y}_{2}$ : flavor, $\mathrm{Y}_{3}$ : transparency, $\mathrm{Y}_{4}$ : taste, $\mathrm{Y}_{5}$ : hardness, $\mathrm{Y}_{6}$ : springiness, $\mathrm{Y}_{7}$ : overall quality. 
Table 6. Analysis of the predicted model equation for the sensory characteristics of Rubus coreanus jelly

\begin{tabular}{cccccl}
\hline Responses $^{1)}$ & Model & R-squared & F-value & $\begin{array}{c}\text { P-value } \\
\text { Prob }>F^{2)}\end{array}$ & Equation of on terms of pseudo component \\
\hline $\mathrm{Y}_{1}$ & Linear & 0.6483 & 7.37 & $0.0046^{*}$ & $4.49-0.49 \mathrm{X}_{1}-0.043 \mathrm{X}_{2}+0.26 \mathrm{X}_{3}$ \\
$\mathrm{Y}_{2}$ & Linear & 0.6839 & 8.65 & $0.0025^{* *}$ & $4.36+0.58 \mathrm{X}_{1}+0.067 \mathrm{X}_{2}-0.033 \mathrm{X}_{3}$ \\
$\mathrm{Y}_{3}$ & Linear & 0.7582 & 12.54 & $0.0005^{* * *}$ & $4.41-1.00 \mathrm{X}_{1}-0.100 \mathrm{X}_{2}+0.17 \mathrm{X}_{3}$ \\
$\mathrm{Y}_{4}$ & Linear & 0.5862 & 5.67 & $0.0118^{*}$ & $4.45+0.41 \mathrm{X}_{1}-0.41 \mathrm{X}_{2}+0.046 \mathrm{X}_{3}$ \\
$\mathrm{Y}_{5}$ & Quadratic & 0.9653 & 18.54 & $0.0010^{* * *}$ & $\begin{array}{l}5.34+0.042 \mathrm{X}_{1}-0.068 \mathrm{X}_{2}+0.13 \mathrm{X}_{3}-0.11 \mathrm{X}_{1} \mathrm{X}_{2} \\
-0.21 \mathrm{X}_{1} \mathrm{X}_{3}+0.062 \mathrm{X}_{2} \mathrm{X}_{3}-1.10 \mathrm{X}_{1}{ }^{2}-0.35 \mathrm{X}_{2}^{2}-0.097 \mathrm{X}_{3}{ }^{2}\end{array}$ \\
\hline
\end{tabular}

${ }^{1)} \mathrm{Y}_{1}$ : color, $\mathrm{Y}_{2}$ : flavor, $\mathrm{Y}_{3}$ : transparency, $\mathrm{Y}_{4}$ : taste, $\mathrm{Y}_{5}$ : overall quality.

${ }^{2)}$ Linear ${ }^{*} \mathrm{p}<0.05,{ }^{* *} \mathrm{p}<0.01,{ }^{* * *} \mathrm{p}<0.001$.

${ }^{3)} \mathrm{X}_{1}$ : Rubus coreanus juice $(\mathrm{g}), \mathrm{X}_{2}$ : gelatin $(\mathrm{g}), \mathrm{X}_{3}$ : sucrose $(\mathrm{g})$.
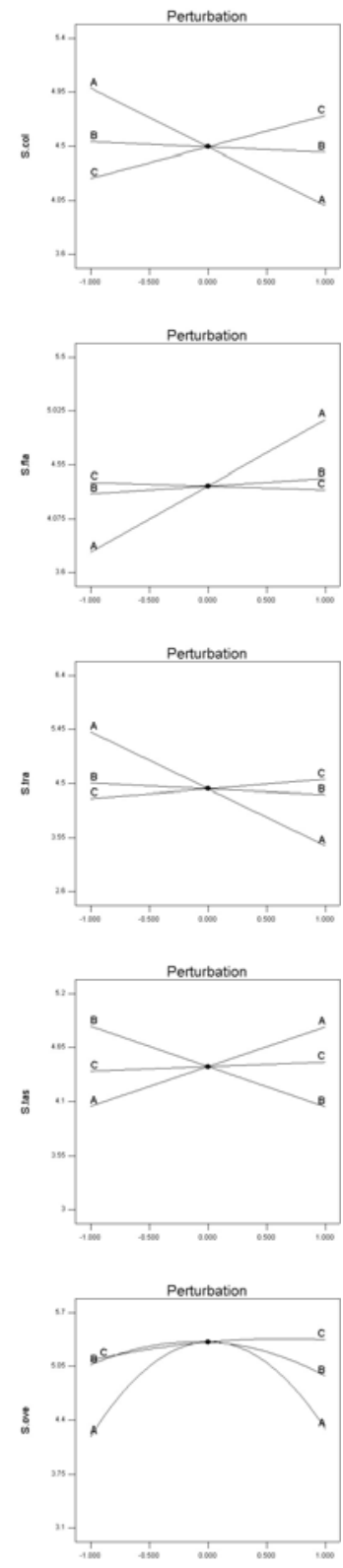
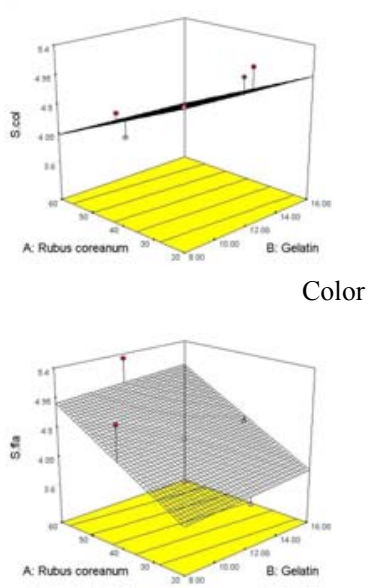

Flavor

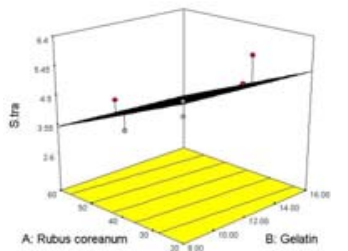

Transparency
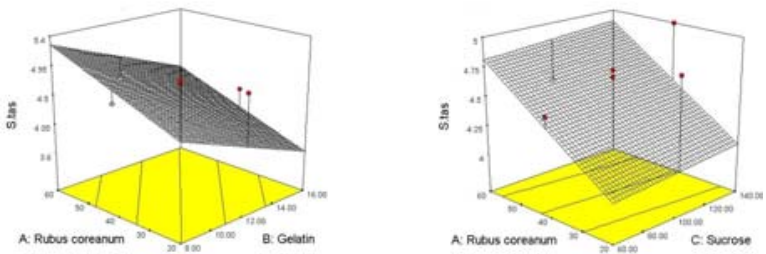

Hardness
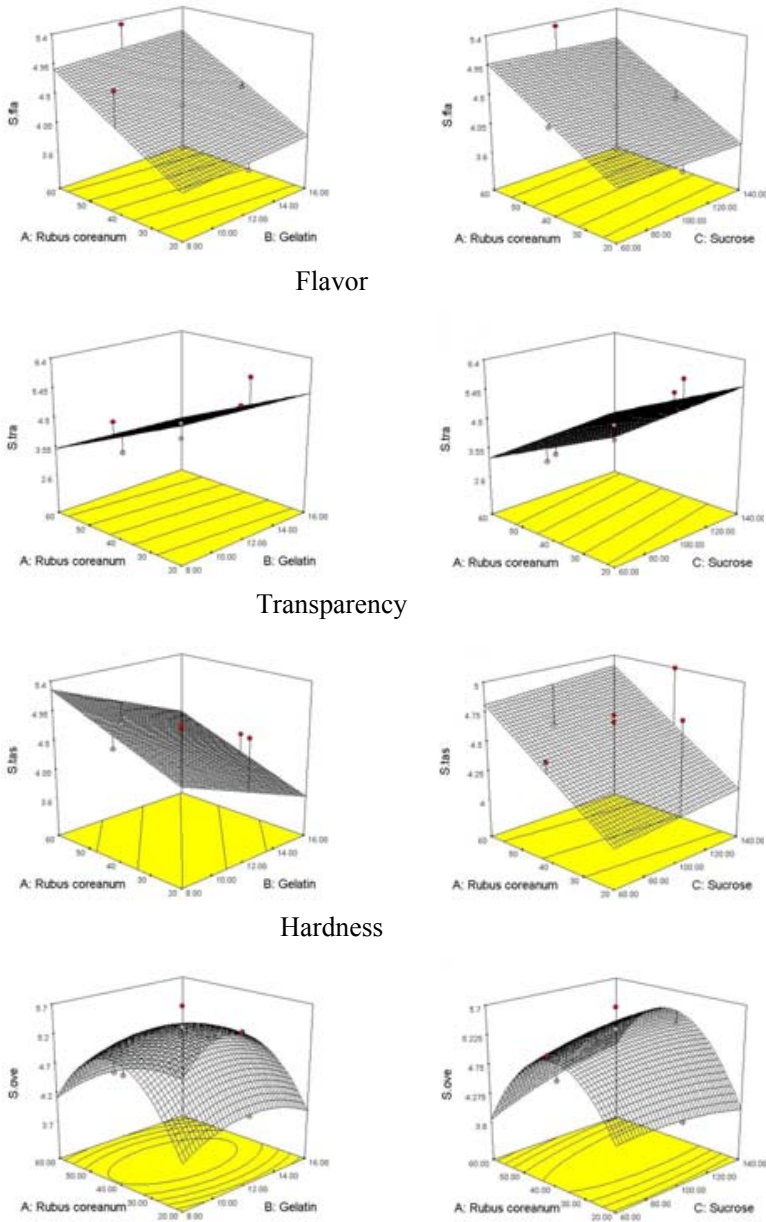
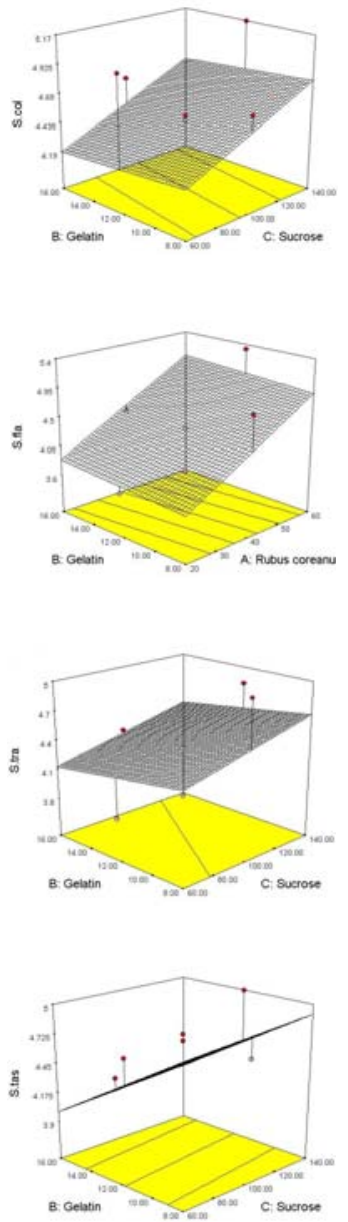

Overall quality

Rubus coreanus juice (A) $\times$ gelatin (B) Rubus coreanus juice (A) $\times$ sucrose (C) $\quad$ gelatin (B) $\times$ sucrose (C)

Fig. 3. Response surfaces for the effect of Rubus coreanus juice (A), gelatin (B), sucrose (C) on sensory characteristics of Rubus coreanus jelly. 


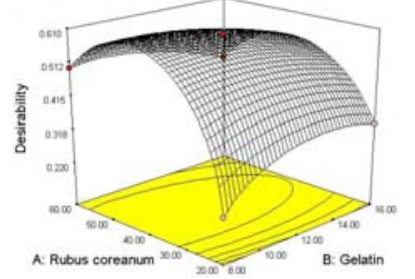

Rubus coreanus juice $(\mathrm{A}) \times$ gelatin $(\mathrm{B})$

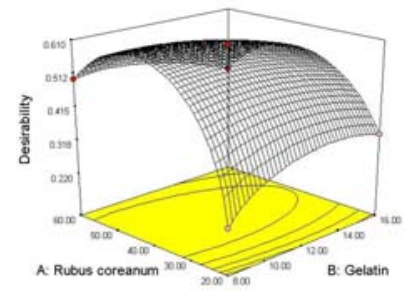

hub coreanus juice $(\mathrm{A}) \times$ sucrose $(\mathrm{C})$

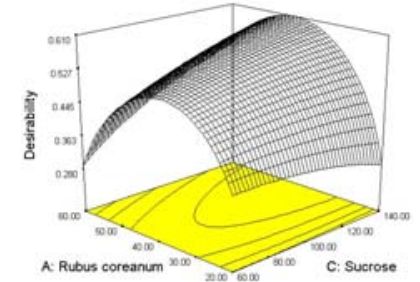

gelatin $(B) \times$ sucrose $(C)$
Fig. 4. Response surfaces plots for optimizing the mixture on desirability of Rubus coreanus jelly.
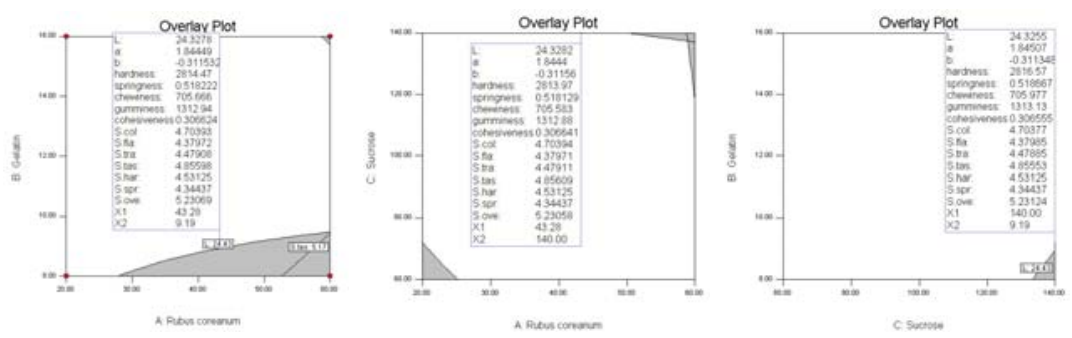

Fig. 5. Overlay plot of the common area for the optimization of the mixture of Rubus coreanus jelly. the addition of Rubus coreanus juice had a positive effect on the sensory evaluation results.

It was shown that the increased addition of Rubus coreanus juice initially improved the overall quality of thejelly, but as more juice as added the overall quality then declined. An increased addition of gelatin contributed to a decreased overall quality of the final product; additional sucrose showed little influence on the overall quality of the jelly. Shown in Fig. 3 is the response surface for the effect of Rubus coreanus juice, gelatin and sucrose on sensory characteristics on Rubus coreanus jelly.

\section{Optimization}

The optimal amounts of Rubus coreanus juice, gelatin and sucrose were selected through numerical optimization of a canonical model and through graphical optimization. The significant items shown in the sensory evaluation were determined by their maxima. This was taken from the response formula determined by the modeling. The numerical point was selected through numerical optimization (Fig. 4) and graphical optimization (Fig. 5). The optimal point with the highest desirability was deduced through point prediction, and the predicted optimal values were $43.28 \mathrm{~g}$ of Rubus coreanus juice and $9.19 \mathrm{~g}$ of gelatin for every $140.00 \mathrm{~g}$ of sucrose.

\section{CONCLUSIONS}

Central Composite Design was used for the purpose of optimizing the manufacturing conditions for Rubus coreanus jelly. The compositional and functional properties were measured, and these values were applied to a mathematical model. A canonical form and perturbation plot showed the influence of each ingredient on the final product. The sensory evaluation results showed sig- nificant values in color $(\mathrm{p}<0.01)$, flavor $(\mathrm{p}<0.01)$, transparency $(\mathrm{p}<0.001)$, taste $(\mathrm{p}<0.05)$ and overall quality $(\mathrm{p}<0.001)$. The optimal sensory ratio was determined to be $43.28 \mathrm{~g}$ of Rubus coreanus juice and $9.19 \mathrm{~g}$ of gelatin for every $140.00 \mathrm{~g}$ of sucrose.

Through the results of the present study, Rubus coreanus jelly was considered to be competitive compared to existing products in functionality, quality and preference. Optimization of the mixing ratios are required to satisfy consumer preferences and their evaluation will be the subject of further research.

\section{ACKNOWLEDGEMENT}

This Research was supported by a 2009 Research Grant from Sookmyung Women's University.

\section{REFERENCES}

1. Devareddy L, Hooshmand S, Collins JK, Lucas EA, Chai SC, Arjmandi BH. 2008. Blueberry prevents bone loss in ovariectomized rat model of postmenopausal osteoporosis. J Nutr Biochem 19: 694-699.

2. Murphy RR, Renfroe $\mathrm{MH}$, Brevard PB, Lee RE, Gloechner JW. 2007. Cooking did not decrease antioxidant capacity of wild blueberries. J Am Diet Assoc 107: A53.

3. Bae GH. 2000. The Medicinal Plants of Korea. Kyohak Publishing Co., Seoul, Korea. p 231.

4. Pang, GC, Kim MS, Lee MW. 1996. Hydrolyzable tannins from the fruits of Rubus coreanus. Korean J Pharmacogn 27: 366-370.

5. Kim HC, Lee SI. 1991. Comparision of the pharmacological effect of kinds Rubi fructus. Korean J Herbology 6: 3-12.

6. Costantino L, Albasini A, Rasteli G, Benvenuti S. 1992. Activity of polyphenolic crude extracts as scavengers of superoxide radicals and inhibitors of xanthine oxidase. 
Plant Med 58: 342-435.

7. Kahkonen MP, Hopia AI, Vuorela HJ, Rauha JP, Pihlaja K, Kujala TS, Heinonen M. 1999. Antioxidant activity of plant extracts containing phenolic compounds. J Agric Food Chem 47: 3954-3962.

8. De Ancos B, Gonzalez EM, Cano MP. 2000. Ellagic acid, vitamin $\mathrm{C}$ and total phenolic contents and radical scavenging capacity affected by freezing and frozen storage in raspberry fruit. J Agric Food Chem 48: 4565-4570.

9. Kwon KH, Cha WS, Kim DC, Shin HJ. 2006. A research and application of active ingredients in Bokbunja (Rubus coreanus Miquel). Korean J Biotechnol Bioeng 21: 405-
409.

10. Gouveia L, Batishts AP, Miranda A, Empis J, Raymundo A. 2007. Chlorella vulgaris biomass used as colouring source in traditional butter cookies. Inn Food Sci Emerg Technol 8: 433-436.

11. Park SP, Joo NM. 2006. Optimization of jelly with addition of Morinda citrifolia (Noni) by response surface methology. Korean J Food Cookery Sci 22: 1-11.

12. Han GH. 2004. Stimulation and the establishment of optimization in new product development using food by product. PhD Dissertation. Kyunggi University, Korea. $\mathrm{p}$ 4-5.

(Received December 8, 2008; Accepted April 16, 2009) 